\title{
Torres de babel e línguas de fogo: um pouco sobre pesquisa na formação de professores de inglês ${ }^{1}$
}

Towers of Babel and Tongues of Fire: A Few Thoughts about Research in English Teachers' Education

Elaine Mateus*

Universidade Estadual de Londrina

RESUMO: O propósito deste texto é discutir a prática social da pesquisa em Lingüística Aplicada em sua relação dialética com as iniciativas de formação de professores de inglês. Para isso, apresento possibilidades de novos territórios que vão sendo desenhados em atividades que buscam romper com relações históricas de poder e de privilégio do conhecimento acadêmico sobre o conhecimento cotidiano. Os participantes envolvidos nessas práticas são quase sempre movidos pelo desejo de diálogo, de não domínio, de emancipação. Sem a ilusão de que os limites entre universidade-escola possam ser completamente apagados, o que se discute aqui é o fortalecimento de uma agenda de pesquisa em Lingüística Aplicada que, sendo atividade crítico-praxiológica, promova unidade na multiplicidade, convergência na pluralidade, ética na não-indiferença.

PALAVRAS-CHAVE: formação de professores de inglês, pesquisa sócio-históricocultural, universidade-escola, atividade crítico-praxiológica

ABSTRACT: This text aims at discussing the dialectics between research practice in Applied Linguistics and EFL teacher education initiatives. Such a discussion is illustrated with possibilities of new territories drawn in activities designed to overcome historical power relations and the privilege of academic knowledge over everyday knowledge. Participants involved in such social practices are motivated by a dialogical emancipatory desire. Bearing in mind that the university-school boundaries cannot be fully eradicated, this article argues for the strengthening of

*mateus@uel.br

${ }^{1}$ Texto base da mesa-redonda Pesquisa e a Formação do Profissional da Linguagem, durante o II ENIEDUC - Encontro Interdisciplinar de Educação, realizado pela Faculdade Estadual de Ciências e Letras de Campo Mourão, em 2008. 
a research agenda that, being a critical-praxiological activity, nurtures singleness within multiplicity, convergence within pluralism, ethics within non-indifference. KEYWORDS: EFL teacher education, social-cultural-historical research, university-school, critical-praxiological activity

\section{Introdução}

Para iniciar a discussão sobre a pesquisa e a formação do profissional da linguagem acho pertinente compartilhar um pouco daquilo que orienta meu trabalho de professora de professores de inglês. Primeiramente, não sou uma especialista em pesquisa e em metodologia de pesquisa. Também não sou uma especialista em formação de profissionais da linguagem. De fato, o universo do meu conhecimento é pequeno e bastante restrito a poucas iniciativas de formação de professores de inglês, antes mediadas por práticas qualitativointerpretativistas de pesquisa, e, mais recentemente, por atividade críticopraxiológica de aprendizagem, conceito ao qual retorno mais adiante.

Por hora, é suficiente saber que essa ressignificação teórico-filosóficometodológica não é fortuita. Ao longo das experiências vividas, tenho me convencido sempre mais de que não se pode pensar sala de aula e pesquisa como diferentes pólos, como dois mundos orientados ora pela prática, ora pela teoria. Ao contrário, acredito que a atividade de fazer ciência e a atividade de ensinar-aprender têm a mesma natureza; são, de fato, "diferentes camadas da mesma realidade da atividade humana transformativo-colaborativa" ${ }^{2}$ (STETSENKO; ARIEVITCH, 2002, p. 67).

A ressignificação do meu trabalho decorre, portanto, de um processo histórico-social de ressignificação do que é conhecimento e de como aprendemos. Essa trajetória se reflete na presente discussão em que conhecimento é definido como aquilo que emerge na práxis, isto é, no processo intencional de transformação das experiências vividas, e aprendizagem é caracterizada como uma atividade social situada em contextos específicos, distribuída entre os participantes e mediada por artefatos, dentre os quais, a linguagem.

Assim, o objetivo deste texto é refletir sobre um tipo de pesquisa que, forjada em práticas sócio-educacionais revolucionárias, promove a transformação das identidades dos professores, de suas práticas e dos processos de ensinoaprendizagem nos quais elas ocorrem. Falar de pesquisa forjada em prática

\footnotetext{
${ }^{2}$ Todas as traduções são livremente feitas por mim.
} 
revolucionária aproxima esta discussão dos estudos de base marxista em que consciência revolucionária significa "atividade prático-crítica da vida diária" (NEWMAN; HOLZMAN, 1993/2002, p. 101). Trata-se, deste modo, de pesquisa que, baseada no método da estimulação dupla (VYGOTSKY, 1998), se desenha não para explicar os fenômenos, mas para recriá-los.

Isso significa dizer que, como se verá ao longo dos argumentos apresentados, essa é uma discussão sobre pesquisa de base materialista-dialética que, por não poder ser compreendida senão como processo deliberado de transformação das realidades sociais, é por natureza transformadora daqueles que nela se envolvem e que dela se apropriam. É um artigo permeado, portanto, por reflexões sobre questões de privilégio, tensão, voz e poder presentes nos discursos sacralizados (CHEYNE; TARULLI, 2004) e nos princípios que legitimam as práticas sociais, tanto na escola quanto na universidade (CAMERON et al., 1992).

Para tanto, tomo por base o referencial teórico da corrente sóciohistórico-cultural como uma das possibilidades de análise, de crítica e de transformação da essência do fenômeno social em foco. Como veremos, esse é um arcabouço que permite um olhar dialético sobre os processos de práticapesquisa e sobre as relações humanas que se deseja conhecer e transformar.

É importante dizer que não proponho essa como a única ou a mais relevante perspectiva para se discutir pesquisa educacional. Tenho clareza de que diferentes concepções de ser humano e de conhecimento orientam diferentes perspectivas teóricas: cada qual com suas contribuições e contradições. No entanto, argumento que uma agenda de pesquisa pautada em princípios de cuidado com o outro, de colaboração genuína entre professores - os chamados formadores e aqueles em formação - e em experiências de transformação da práxis na práxis pode contribuir para a produção de novas culturas e de novos sentidos para o trabalho docente.

\section{Torres de Babel: os distantes mundos do formador e do professor}

A história da Torre de Babel é provavelmente uma das mais conhecidas da bíblia. O livro do Gênesis conta que os descendentes de Noé, interessados na eternidade, começaram a construir uma torre alta o suficiente para alcançar Deus que, irado com tanta soberba, decidiu confundi-los. Para isso, fez com que começassem a falar línguas diferentes. Diante da impossibilidade de se entender, as pessoas dispersaram-se por toda a terra. 
Essa é uma história que, ao seu modo, busca explicar a multiplicidade de línguas e a divisão entre os povos. Por isso, a referência à Torre de Babel indica conflito, separação, incapacidade de compreensão mútua. E é nesse sentido que uso essa imagem para começar nossa reflexão sobre as pesquisas educacionais e, mais pontualmente, sobre pesquisa na formação de professores de inglês.

Sabemos que as décadas de 80 e 90 foram fortemente marcadas por críticas à tradição de pesquisa positivista pautada no rigor metodológico, na objetividade e na generalização como indicadores de cientificidade. Tanto a Lingüística Aplicada quanto a Educação, influenciadas pelos cientistas sociais do período, buscaram outras formas de compreender os fenômenos a partir de suas especificidades, construídas nas relações sociais. As pesquisas qualitativas se fortaleceram, desse modo, como espaço de observação da realidade "como ela é" (CAMERON et al., 1992, p. 7) e de produção de conhecimento sobre novas bases epistemológicas (BREDO; FEINBERG, 1982).

$\mathrm{Na}$ área da Lingüística Aplicada vimos florescer pesquisas que buscavam resolver "problemas de prática de uso da linguagem dentro e fora da sala de aula" (MOITA LOPES, 1996, p. 3). Muitos desses estudos estavam voltados para a compreensão e para a interpretação das complexidades que envolvem o trabalho dos professores como, por exemplo, o que eles sabem e no que acreditam, seus processos de socialização, de que modos aprendem e lidam com a sala de aula. Nesse cenário, os professores de línguas estrangeiras "passaram a ser vistos como aqueles que tomam decisóes e que se beneficiam ao tornar explícitos seu conhecimento tácito e suas decisões" (JOHNSON, 2006, p. 236).

Os sentidos de professor reflexivo e de professor pesquisador permearam muitas iniciativas na área de formação de professores de inglês nesse período (RICHARDS; NUNAN, 1990; WALLACE, 1991; FREEMAN; RICHARDS, 1996; RICHARDS, 1998, entre outros). No entanto, embora as pesquisas tivessem se voltado para a cognição dos professores e suas práticas em sala de aula, os processos e resultados não foram suficientes para aproximar as diferentes faces do mesmo fenômeno. As tensões entre teoria e prática agravaram o distanciamento entre pesquisadores e professores, universidade e escola, conhecimento científico e conhecimento cotidiano, entre saber e fazer. Tantas outras torres foram erguidas. Dessa vez, cercadas por muros que marcam os territórios e guardadas por práticas e discursos sacralizados, seja pela visão profética da ciência, seja pelo currículo escolar ou pelo senso comum (CHEYNE; TARULLI, 2000, p. 18). 
Do modo como vejo, há, pelo menos, três razões que permitem compreender essa divisão. Uma delas está no fato do modelo de formação reflexiva e de professor pesquisador ter sido fortemente produzido sob o manto do método do pensamento científico deweyano, centrado na busca racional de soluções para problemas da prática e na autodeterminação descolada das forças sócio-histórico-culturais nas quais as sociedades existem (BENGTSSON, 1995, MATEUS, 2005). Dewey baseava-se na associação entre pensamento reflexivo e método científico para assegurar que as açôes impulsivas fossem transformadas em açóes inteligentes (FENDLER, 2003).

Assim, muito do que se produz sob o rótulo da pesquisa-ação ou da pesquisa-ação participativa encontra suas raízes no pensamento científico convencional no que diz respeito à natureza do conhecimento válido, isto é, considera que "a ciência pode contribuir para que as pessoas percebam seus valores, vislumbrando um futuro melhor e se organizando de modo eficaz para alcançá-lo" (BRAY et al., 2000, p. 35). De fato, vários trabalhos definidos como críticos ou dialéticos seguem, em sua base epistemológica, os parâmetros positivistas em que pesam métodos não interativos, relações de causa e efeito e resultados apresentados como fatos ou verdades. Para Cameron e colaboradores (1992, p. 7), essa hegemonia decorre do "'senso comum' dominante da ciência moderna”.

Outra razão para o distanciamento do pesquisador e do professor está no fato de que muitos trabalhos, inclusive os ditos colaborativos, são feitos sobre o outro ou para o outro (CAMERON et al., 1992). Mesmo no campo da pesquisa-ação, não são raras as agendas predominantemente definidas pelos "pesquisadores" e os resultados usados para beneficiar, antes e acima de tudo, aqueles para quem "fazer pesquisa" implica em reconhecimento social e material. Nesse quadro, as representações culturais-sociais que a academia produz dos professores que investiga contribuem para fortalecer o status do pesquisador sobre o professor e para reproduzir as desigualdades entre ambos. É significativo o número de relatos em que os professores "têm sido referidos como tecnocratas, sexistas, racistas, incompetentes e mediocremente superficiais" (ZEICHNER, 1998, p. 212). Mais recentemente, Kleiman (2001, p. 42) também denuncia pesquisas em que os professores formadores de leitores são descritos como leitores interditados, como representantes não confiáveis da cultura letrada e até mesmo como não-leitores. Só o fato da academia se sentir autorizada a produzir e tornar públicas tais representações é, por si, revelador das relações de poder que historicamente têm alimentado um bom número de pesquisas educacionais. 
A terceira razão está no foco que a tradição das pesquisas de sala de aula dá ao nível micro da análise das interações sociais. Mesmo considerando o professor como sujeito social forjado na interação com a cultura e a história de seu tempo, há muitos trabalhos que tendem a considerar o contexto social e histórico de forma superficial e benéfica. Freitas (2003, p. 5) argumenta que

o pesquisador, ao interrogar-se diante do outro tomando a cultura como objeto de descrição analítica e de reflexão interpretativa, continua ainda numa posição privilegiada em relação à produção do conhecimento sobre o outro.

Assim, a centralidade na aprendizagem individual, na interação de díades ou de grupos e no contexto descolado de ideologias e de relaçóes de poder tem efeitos sobre "a produção do conhecimento e sobre os tipos de conhecimento que são legitimados" (VADEBONCOUER, 1997, p. 27). Ao tomar o contexto em seu aspecto descritivo (por exemplo, tamanho e localização da escola, número de salas, quantidade de alunos, etc.), valores culturais que deveriam ser ressignificados vão sendo reproduzidos e as "verdades" sobre os professores vão sendo apropriadas pela sociedade. Com isso, a academia, ainda que motivada por razôes diametralmente opostas, acaba por contribuir para socializar os professores num discurso alienado e mistificado que pouco tem a ver com as realidades de seu cotidiano.

Isso porque, assim com as pesquisas feitas sobre ou para professores, aquelas que fogem a uma análise do contexto como espaço próprio de (re)produção social, de legitimação de vozes, de possibilidades de ação mediadas por práticas culturais tendem a responsabilizar os próprios professores pelo insucesso da educação. Teorias que reduzem o desenvolvimento a capacidades individuais e pesquisas que reduzem o contexto a pano de fundo no qual a prática investigada acontece acabam por "culpar os marginalizados pela marginalidade" (LAVE, 1996, p. 149). Como resultado, o que se tem é uma ruptura sujeito e objeto, consciência e realidade, instrumento e resultado, mundo da teoria e mundo da vida.

Diante desse quadro, cada vez mais professores sentem a necessidade de ressignificar as relações pesquisador-pesquisado, saber-fazer, universidadeescola. A contradição entre teoria e prática tem produzido outros sentidos do que seja fazer pesquisa e formar-se professor. Como discuto a seguir, esses são processos que vão além das aparências. Não se trata, portanto, de vinho novo em talhas velhas. Iniciativas que buscam romper com as relações históricas de 
poder e privilégio da universidade sobre a escola envolvem transformações na essência das práticas sociais de pesquisa-formação.

\section{Línguas de fogo: o encontro na diversidade}

Desde a última década, os campos das Ciências Sociais e Humanas protagonizam a chamada "virada sócio-histórico-cultural" nas pesquisas e nas práticas de formação de professores. Engendrada nos fios que tecem presentepassado-futuro, a história recria o sentido de aprendizagem humana como uma atividade dinâmica, de natureza social, culturalmente situada e distribuída no tempo entre as pessoas (VYGOTSKY, 1978/1998; ENGESTRÖM, 1987, 1996/2005, 1999, 2001/2005; LAVE; WENGER, 1991; COLE; ENGESTROM, 1993; LAVE, 1996; ROGOFF, 1995, 2003).

Isso significa dizer que o ser humano aprende e se desenvolve no processo da experiência social prática, mediada por modos particulares de se inter-relacionar com o outro, com a cultura, com a linguagem e com aquilo que os momentos sócio-históricos permitem em determinadas comunidades de prática. Sendo, portanto, gerada no curso da ação, do pensamento e do diálogo com outros participantes, a aprendizagem se constitui movimento criativo de transformação de si e das realidades nas quais os sujeitos existem.

Assim, enquanto numa concepção cognitivista de aprendizagem o foco está na mudança que se deseja provocar no outro conforme definida e guiada pelo "par mais experiente", na visão sócio-histórico-cultural aprendizagem está voltada para a transformação da participação dos envolvidos nas práticas sociais situadas (LAVE, 1996; MATUSOV; HAYES, 2002); práticas essas que constituem as circunstâncias concretas de suas vidas e que influenciam sua identidade, seus conhecimentos e seu lugar social nas relaçôes interpessoais (LEONTIEV, 1998). A aprendizagem nessa perspectiva, explica Kastrup (2005, p. 1273), "não é um processo de solução de problemas, nem a aquisição de um saber, mas um processo de produção de subjetividade". Desenvolverse significa, portanto, "mudar o curso da vida, incluindo a rejeição destrutiva do velho, juntamente com outras pessoas de importância, e por meio da transposição de fronteiras entre mundos" (ENGESTROM, 1996/2005, p. 44).

Sendo elemento da práxis, a linguagem é também caracterizada como um produto social, encharcada de posições axiológicas, tecida nas tramas dos conflitos e das posiçôes sociais dos sujeitos. A exemplo do sentido de aprendizagem socialmente produzida, o discurso não é aqui tomado como neutro e abstrato, mas como ação situada em contextos de atividade prático- 
crítica. A releitura de Bakhtin no cenário contemporâneo é um importante instrumento que permite ressignificar a linguagem como artefato social que não somente reflete o mundo, ou seja, aponta para uma realidade que lhe é externa ou designa o objeto como uma realidade pronta, mas que também o refrata, isto é, produz efeitos de sentido e múltiplas interpretaçôes desse mundo, com base nas experiências sócio-histórico-culturais. Tomando a linguagem como elemento produzido e reproduzido no interior da prática social, Bakhtin busca, então, na metáfora do diálogo, a caracterização do movimento inerente ao universo da criação ideológica. Para ele, linguagem e práxis são, em essência, indissociáveis:

A vida é por natureza dialógica. Viver significa participar no diálogo: fazer perguntas, tecer considerações, responder, concordar e assim por diante. Nesse diálogo, a pessoa participa integralmente e ao longo de toda sua vida: com seus olhos, lábios, mãos, alma, espírito, com todo seu corpo e alma. (BAKHTIN, 1984, p. 293)

O campo da Lingüística Aplicada que se orienta por essa concepção tem voltado sua atenção para contextos de práxis marcados por relaçóes de poder e por conflitos de vozes que dão forma e são formados por identidades em constante devir (MOITA LOPES, 1996). Dentro de uma perspectiva mais crítica, explica Liberali (2006, p. 1),

a LA enfoca as transformações das condiçōes de injustiça dentro das quais os sujeitos circulam. Portanto, sua perspectiva aplicada, nada tem a ver com a aplicação de conhecimentos lingüísticos, mas sim com a transformação aplicada das condições sociais a partir da análise, compreensão e redimensionamento dos aspectos lingüísticos que compõem as ações humanas.

Desse modo, a reconceitualização do ser humano como agente de transformação da e na história, da cognição humana como social, situada e distribuída, e da linguagem como confronto de múltiplas vozes, ressignifica também o paradigma de pesquisa como uma "relação entre os sujeitos, portanto dialógica, na qual o pesquisador e pesquisado são partes integrantes do processo investigativo e nele se ressignificam" (FREITAS, 2003, p. 28). Pesquisa, assim definida, é inerente ao processo de ser-com-outro; é, por natureza, o lugar de encontro com o outro e de (re)criação de si no mundo e não pode, portanto, ser compreendida senão em sua relação dialética com a aprendizagem. 
Os conceitos de alteridade e de exotopia, conforme discutidos pelo Círculo de Bakhtin, ${ }^{3}$ são essenciais para se compreender este sentido de pesquisa como atividade crítico-praxiológica.

Como discuti até aqui, a virada sócio-histórico-cultural coloca, no cerne ontológico e epistemológico, a dinâmica da relação com o outro como elemento que permite o próprio sujeito social. Isto significa dizer que a existência de um $e u$ só é possível por meio do encontro permanente desse eu com muitos outros que constituem a cultura; encontro esse mediado por práticas sócias e discursivas particulares e prenhes de ideologias. É por meio do outro que nos reconhecemos como sujeitos e recriamos nossas identidades profissionais, raciais, sexuais, étnicas, religiosas e incontáveis outras que se forjam no interior das relaçôes que vivemos. Moita Lopes (1996, p. 6) esclarece que "é a presença do outro com quem interagimos que, em última análise, nos faz ser quem, como e por que somos através do envolvimento no discurso".

No campo das Ciências Humanas, Amorim (2001, p. 26) atribui à alteridade "uma dimensão de estranheza porque não se trata do simples reconhecimento de uma diferença, mas de um verdadeiro distanciamento: perplexidade, interrogação, em suma, suspensão da evidência”. Isso significa dizer que não se trata de reproduzir o outro como ele próprio se vê, mas de dar ao outro um acabamento que decorre da tensão de valores e dos diferentes lugares que cada ator ocupa na cena enunciativa. Em um trabalho mais recente, Amorim (2003, p. 14) explica que "entre o retrato que faço de alguém e o retrato que ele faz de si mesmo, há sempre uma diferença fundamental de lugares e, portanto, de valores".

Nisso consiste o sentido de exotopia (outsideness) que coloca cada indivíduo numa posição única e concreta, que somente ele pode ocupar naquele dado momento e que, por esta razão, o torna responsável pela prática sócio-discursiva que assina. Participação responsável é, dessa forma, pressuposto da relação ética entre eu-outro. Para a pesquisa como prática dialógica, alteridade e exotopia são artefatos conceituais que medeiam as relações sociais pesquisador-pesquisado e a produção de conhecimento que deixa de ser, primordialmente, uma commodity - que beneficia, especialmente, o pesquisador com reconhecimento social e financeiro - para se constituir

${ }^{3}$ Círculo de Bakhtin é uma expressão correntemente utilizada para identificar o conjunto das obras dos filósofos Russos Mikhail Bakhtin, Valentin Volochinov e Pavel Medvedev. 
instrumento de aprendizagem e de agentividade humana. Dito de outro modo, se o outro nos constitui, e nós a ele, como pensar na pesquisa que busca transformar as condições de injustiça sem que isso implique transformar também nossos modos de interagir com outros professores e de agir nas comunidades escolares?

A representação das línguas de fogo diz respeito a esses aspectos. Ao contrário do castigo vivido pelos descendentes de Noé, aqui o poder de Deus é apresentado como alento. Está no livro de Atos dos Apóstolos que no dia de Pentecostes, uma festa cristã e judaica realizada para celebrar as colheitas, os apóstolos viram descer dos céus o Espírito Santo em forma de línguas de fogo que pousaram sobre suas cabeças. Depois disso, começaram a falar as diferentes línguas dos diferentes povos que estavam reunidos em Jerusalém para aquela festa.

Se a Torre de Babel simboliza distanciamento de mundos e divisão entre povos, as línguas de fogo simbolizam, por sua vez, unidade na multiplicidade, que decorre dessa possibilidade de entendimento nas diferenças; convergência na pluralidade, que decorre do caráter ecumênico da festa que reunia pessoas de todas as raças e condições sociais; e compromisso ético, que decorre do valor pedagógico da partilha e do cuidado com o outro.

Esses são princípios que definem a natureza da atividade críticopraxiológica à qual me referi como possibilidade para a pesquisa na formação dos professores de inglês. Por ser dialógica, o resultado ou o produto da pesquisa não se dissocia da metodologia já que essa última pressupõe a participação ativa na práxis que se deseja conhecer e transformar. Isto é, não se trata de fazer pesquisa como se sujeito e conhecimento fossem independentes um do outro, mas trata-se de inserir-se no universo da práxis a fim de enfrentar suas contradiçōes e, nesse processo, produzir conhecimento localmente significativo.

Atividade crítico-paraxiológica diz respeito, portanto, à busca de explicaçōes sobre a práxis, fundada na práxis e desenvolvida a partir da práxis (ROTH; LAWLESS; TOBIN, 2000). Isto é, diz respeito à teoria que nasce da práxis e que retorna à práxis a fim de transformá-la de modo que faça sentido àqueles que dela participam. Não é, desse modo, teoria que se deve aplicar para resolver problemas do cotidiano escolar. Não é também conhecimento tácito que não se pode teorizar. Atividade crítico-praxiológica significa, de modo simples, a dialética ensino-e-pesquisa, instrumento-e-resultado, aprendizageme-desenvolvimento. É a teoria que, gerada na prática, retorna ao mundo da teoria para se consolidar e se renovar continuamente "por meio de um vínculo orgânico" que mantém com essas mesmas práticas (FARACO, 2003, p. 61). 
Isso quer dizer que tanto a razão teórica prescinde da prática para se consolidar e renovar quanto a razão prática prescinde da teórica para recriar possibilidades de ação e de transformação. Assim, a lacuna entre a descrição da prática feita por acadêmicos e a prática propriamente dita, vivida por professores, diminui na medida em que aquilo que se fala sobre o mundo da vida e sobre as demandas da sala de aula decorre do esforço real de pessoas reais envolvidas na transformação de contextos também reais.

O que está posto nesta discussão, portanto, é a ressignificação radical do lugar da teoria e da prática no esforço de aproximação dos mundos universidade-escola. Nas práticas hegemônicas predominantes nas pesquisas modernas e nos modelos de formação de professores, o caminho tem sido partir da transmissão do conhecimento científico que, uma vez assimilado, pode ser transposto para outras situações da vida dos professores e, assim, eventualmente transformar suas práticas de sala de aula. No entanto, na perspectiva dialógica bakhtiniana na qual a atividade crítico-praxiológica encontra suas raízes,

não é possível superar este dualismo partindo do interior da cognição teórica. Essa superação só será alcançável subsumindo a razão teórica na razão prática, entendida essa como a razão que se orienta pelo evento único do ser e pela unicidade de seus atos efetivamente realizados; ou, em outras palavras, que se orienta a partir do vivido, i.e., do interior do mundo da vida. (FARACO, 2003, p. 20)

O conhecimento produzido nos contextos de práxis implica o desenvolvimento de quem conhece e, ao mesmo tempo, a transformação qualitativa daquilo que é conhecido. Como explica Bakhtin (1992, p. 352), "em um encontro dialógico, as duas culturas não se fundem, nem se mesclam, cada uma conserva sua unidade e sua totalidade aberta, porém ambas se enriquecem mutuamente".

Essa é uma perspectiva que se contrapõe às propostas orientadas pelo modelo do pesquisador colonizador que vai à escola mudar o trabalho do professor, sempre "primitivo", ou que busca no encontro com o outro um modo de transmitir sua cultura. Se contrapóe também ao modelo do pesquisador extrativista cujo interesse está em retirar da escola os dados para produzir conhecimento que, na maior parte das vezes, não retorna aos envolvidos. Ao contrário, atividade crítico-praxiológica se produz mediada pelo sentido de bidirecionalidade no processo de socialização (WERTSCH, 1991) em que todos os envolvidos se deixam transformar cognitiva-afetiva- 
emocionalmente. A pesquisa que busca uma transformação concreta das situações educacionais reais envolve "pesquisadores e práticos em uma tarefa comum que transcende a dualidade de papéis da pesquisa e da prática" (CARR; KEMMIS, 1986, p. 158). Se numa perspectiva positivista-individualista a liberdade de um vai até onde começa a liberdade do outro, na concepção crítico-praxiológica ética se define pela liberdade de um que vai até onde pode ir a liberdade do outro. Não são, portanto, os limites entre o eu e o outro que definem as possibilidades de ser de cada um, mas é a relação eu-outro que permite que, juntos, todos possam ser mais.

Essa é uma discussão que nos convida a uma profunda ressignificação dos papéis sociais que estamos habituados a desempenhar, tanto como professores quanto como formadores de professores ou, como prefiro, professores de professores. Há, contudo, iniciativas concretas que buscam transformar as relações de privilégio e de poder da universidade sobre a escola, do formador sobre o professor. Apenas para ilustrar, apresento duas iniciativas realizadas nos Estados Unidos, no campo da educação, e outras duas realizadas no Brasil, no campo da Lingüística Aplicada.

O primeiro exemplo vem de uma experiência de formação multicultural de professores, vivida no projeto La Red Mágica, uma proposta de parceria entre a Universidade de Delaware e o Centro Comunitário América-Latina, na cidade de Wilmington. Iniciado em 1998, tem como finalidade desenvolver um programa extra-curricular baseado nos princípios do trabalho colaborativo que ligue as vidas das crianças de contextos minoritários às práticas de formação de professores para atuarem nesses contextos. Aqui, a aprendizagem é definida como a produção de uma comunidade de educadoresaprendizes e o currículo de formação se cria no contexto de aprendizagem na prática com crianças, muitas delas, imigrantes de baixa renda.

Essa é uma iniciativa que toma como centrais as questões que emergem da realidade vivida e, por meio do confronto dos dilemas, preocupações e desconfortos, busca alternativas e possibilidades de práticas com base naquilo que é localmente significativo. O conhecimento é produzido, portanto, a partir da práxis. Para os professores envolvidos nesse projeto, essa é uma característica que promove a unidade entre o conteúdo e o método da prática de ensino, isto é, entre o conhecimento historicamente produzido e o mundo da vida escolar (MATUSOV; HAYES, 2002).

O que é relevante nessa discussão é precisamente a ressignificação de papéis e o valor dado à pesquisa como mediadora no processo de recriação de práticas e identidades. A partir de uma situação de conflito gerada pelo uso de 
palavróes e xingamentos em espanhol, Matusov e Hayes (2002) falam sobre as tensóes e dificuldades encontradas pelos professores em aprender a lidar com crianças em tantos sentidos diferentes, sem cair na armadilha das representaçōes românticas ou demoníacas presentes nos filmes e nos livros educacionais. Contrariando as práticas mais comuns em que os problemas reais, quando postos à mesa, são resolvidos à luz da teoria já produzida, a experiência que relatam se constrói sobre pontos de vista alternativos, análise das conseqüências desejáveis e indesejáveis de cada possibilidade apresentada e avaliação cuidadosa das açôes pedagógicas sugeridas.

Um segundo exemplo de trabalho que surge em resposta à necessidade de diálogo entre universidade e escola é o que Wolff-Michael Roth e Kenneth Tobin chamam de ensino colaborativo gerador de diálogo produtivo (ROTH; TOBIN, 2001, 2002-a, 2002-b, 2004). Para eles, a aprendizagem de professores na perspectiva crítico-praxiológica envolve mudanças significativas de papéis, assim como uma distribuição menos assimétrica de poder entre os participantes. Nesse sentido, eles discutem de que modos o ensino colaborativo, na medida em que permite aos professores compartilhar a responsabilidade pela aprendizagem dos alunos, oferece um contexto apropriado onde professores possam se desenvolver e os novatos possam aprender a ensinar.

O ensino colaborativo ressignifica o formador como participante ativo na escola pública, o professor-novato como participante legítimo nas salas de aula e o professor colaborador como participante genuíno nos processos decisórios que envolvem o ensino básico. Como argumentam Roth e Tobin (2002-a, p. 121), "o ensino colaborativo é essencial porque permite a emersão de desafios mais significativos e, desse modo, abre possibilidades para se aprender com o outro não somente de modo explícito, mas igualmente e ainda mais importante, de modo tácito". Desse modo, o ensino colaborativo produz as bases comuns sobre as quais os sentidos são posteriormente compartilhados e novas possibilidades são elaboradas. A isso chamam de diálogo produtivo ou metadiálogo, cujo propósito é promover aprendizagem por meio de oportunidades de analisar questôes significativas sob os diversos pontos de vista dos envolvidos no mesmo evento. Nesse modelo, aqueles que vivenciaram uma situação de sala de aula específica, de um ponto de vista similar (como professores) e que se envolveram em tomadas de decisão na mesma temporalidade, compartilham aquilo que lhes é relevante e produzem teoria local a fim promover aprendizagem dos alunos em sala de aula.

Isso nos leva ao próximo conjunto de iniciativas que buscam ir além da divisão pesquisador/professor, agora em contexto nacional. Repito que esta 
discussão serve somente para ilustrar o sentido de atividade crítico-praxiológica e que muitas outras experiências de aproximação dos mundos da teoria e da vida têm sido relatadas tanto no Brasil (consultar, por exemplo, DIETZSCH, 1995; REALI; TACREDI, 2001; CARDOZO, 2003; FOERSTE, 2005), quanto no exterior (por exemplo, ENGESTRÖM, 1994; VADEBONCOEUR, 1997; MATUSOV, 2001; ENGESTRÖM et al., 2002; SMAGORINSKY, et al., 2003, 2004; MOLL; ARNOT-HOPFFER, 2005; ANAGNOSTOPOULOS et al., 2007).

Por sua natureza teórico-prática, as iniciativas que apresento a seguir se dão em programas de extensão-pesquisa: uma delas no Núcleo de Assessoria Pedagógica (NAP) sediado na Universidade Estadual de Londrina, e outra no Programa Ação Cidadã (PAC), que acontece na PUC da São Paulo.

O NAP foi criado em 1989, por formadores de professores de inglês, da UEL. Movido pela necessidade de romper com a concepção de "treinamento" de professores, o programa surgiu como uma opção de formação continuada e de aproximação da universidade com as escolas públicas (consultar GIMENEZ, 1999, no prelo). Ao longo desses anos, apesar de suas transformaçōes (ver MATEUS, CAMARGO-QUEVEDO, GIMENEZ, no prelo), o programa conservou sua vocação transformadora das relações pesquisador-professor, seja por meio de iniciativas que buscam a parceria entre a universidade e as escolas (ORTENZI et al., 2004; FURTOSO et al., no prelo), seja por meio de propostas de ensino colaborativo em comunidades de aprendizagem (MATEUS, 2005, 2006, 2007; GIMENEZ; MATEUS, no prelo).

É importante destacar que as iniciativas que dão vida ao NAP se orientam, cada uma a seu modo, por uma ressignificação nos modos de produção, distribuição e consumo do conhecimento. Na medida em que regras de participação são recriadas, seja na universidade, seja nas escolas, e que diferentes bases de conhecimento são deliberadamente incorporadas ao processo de aprendizagem dos professores, identidades são transformadas de modo significativo.

Em outra oportunidade, relatamos a complexidade desse processo em que professores-colaboradores, professores-formadores e professores-novatos se encontram e se (re)criam, mediados pelas experiências vividas na prática de ensino colaborativo, isto é, pelas possibilidades criadas nesta comunidade de aprendizagem (MATEUS; PICONI, 2007). O texto trata de eventos em que, diante de um dilema que surge na práxis, os participantes questionam seus papéis e expõem uma contradição entre identidades autoritário-monológicas 
em contextos idealizados de práticas democrático-dialógicas (BAKHTIN, 1981; NYSTRAND et al., 1997). Assim como na experiência de Matusov e Hayes (2002), aqui também o foco está sobre os modos como os participantes se envolvem na busca de alternativas e, nesse processo, aprendem à luz dessas práticas sociais.

Tendo em mente a discussão sobre a dialética pesquisa-formação de professores de inglês, a experiência que Mateus e Piconi (2007) relataram possibilita compreender a relação entre aquilo que os professores aprendem e os modos como essa aprendizagem se dá e chama a atenção para o conceito da reciprocidade de papéis. Isso quer dizer que não se pode restabelecer a dialética ação-pesquisa senão no interior da práxis; não se pode formar professores capazes de diálogo fora de práticas dialógicas; não se pode romper com relações de privilégio e de poder sem a legitimação do outro. O desafio para a Lingüística Aplicada, explica Johnson (2006), está em reconhecer os professores como produtores de conhecimento e em integrar seus modos de produção e de práxis às bases de conhecimento que têm dominado a pesquisa e formação tradicional destes profissionais.

Esta é uma reflexão que remete às iniciativas do PAC, um programa embasado nos princípios do trabalho colaborativo de formação crítica para a cidadania como atividade desejável, mediado pela linguagem. "Neste programa”, explicam Liberali e colaboradoras (2006, p. 170), "partimos do pressuposto de que, para a construção de uma escola transformadora, é preciso que, em uma ação conjunta, universidade, escola e comunidade assumam novas formas de pensar e agir sobre a Educação no Brasil".

Comum a muitos projetos que dão vida ao PAC está o conceito mediador de cadeia criativa que Liberali (2006) definiu como engendrada por parceiros numa atividade produzindo significados que são mais tarde compartilhados com outros novos parceiros por meio dos sentidos que eles trazem para a nova atividade. Na prática, esse artefato conceitual destaca, em sua definição, a teia na qual sentidos são produzidos pelos professores e coloca em evidência o fato de que a distribuição cognitiva depende das possibilidades criadas pela ação humana.

A breve descrição desses trabalhos deixa ver a centralidade da colaboração como princípio fundador da atividade crítico-praxiológica. Mais do que isso, esses relatos permitem compreender que, embora a colaboração seja uma condição, ela não é, por si só, garantia de novas fronteiras. Assim como o modelo da reflexão crítica tornou-se, em muitos contextos, instrumento de maior domínio da academia sobre o trabalho da escola (ZEICHNER, 2003), 
também o conceito de colaboração em comunidades de prática pode ser apropriado como ferramenta de controle sobre grupos de professores. Se ao mudarmos mudamos aparência, o resultado é sempre o mesmo. A recriação do sentido que liga pesquisa à prática carece da recriação do sentido de colaboração não como uma somatória de partes, mas como síntese de múltiplas consciências, de múltiplos sentidos, das múltiplas vivências: consciências deliberadamente forjadas para além da pele.

\section{Algumas considerações}

As relaçôes sociais, políticas e econômicas que constituem as práticas de produção de conhecimento e de formação de professores são complexas e seus processos de recriação são longos, tensos e, como apontou Freire (1970), carecem de uma boa dose de esperança e de utopia. Ainda que paradigmas coexistam num processo cíclico de transformação-permanência, diferentes modos de compreender como o conhecimento é produzido e de que formas as pessoas aprendem e se desenvolvem forjam diferentes práticas de pesquisa e de formação de professores.

Podemos dizer que a área de formação de professores encontra-se em seu momento de virada. O desafio está em como vamos responder às demandas que se colocam diariamente à nossa frente. Podemos, como temos feito, nos manter encapsulados em nossos espaços seguros, protegidos do não-saberfazer, das diferenças, do desassossego. Mas podemos, por outro lado, sair dos casulos e migrar como fazem as borboletas - e migrar, nesse caso, significa mais do que voar para longe ou buscar novas fronteiras. Migrar aqui significa disposição para o outro e para práticas não-indiferentes. Como alerta Liberali (2006),

se quisermos uma sociedade mais ética, com respeito pela identidade do outro e estímulo à sua criatividade, com a visão da história como possibilidade, foco na inclusão e na esperança e com desafio à liberdade criativa, é preciso desenvolver instrumentos para tal.

Para isso, precisamos aprender a dialogar com múltiplas perspectivas, produzir análises interinstitucionais e interculturais, criar e fortalecer redes que ligam diferentes pequenos estudos de forma a revelar o impacto dos contextos locais e das situacionalidades culturais. Precisamos criar novos territórios, novos espaços híbridos (GUTIÉRREZ et al., 1999), novas fronteiras em que universidade e escola produzam na práxis formas ousadas de ser no mundo. Precisamos aprender a ouvir mais, a sentir mais e a ser-mais-com-o-outro. 


\section{Referências bibliográficas}

AMORIM, Marilia. O pesquisador e seu outro: Bakhtin nas Ciências Humanas. São Paulo: Musa Editora, 2001. 304p.

AMORIM, Marilia. A contribuição de Mikhail Bakhtin: a tripla articulação ética, estética e epistemologia. In: FREITAS, Maria Teresa; SOUZA, Solange Jobim e; KRAMER, Sonia (Org.). Ciências Humanas e pesquisa: leituras de Mikhail Bakhtin. São Paulo: Cortez, 2003, p. 11-25.

ANAGNOSTOPOULOS, Dorothea; SMITH, Emily; BASMADJIAN, Kevin. Bridging the university-school divide: horizontal expertise and the "two-worlds pitfall”. Journal of Teacher Education, v. 58, n. 2, p. 138-152, March/April 2007. BAKHTIN, Mikhail M. The dialogic imagination: four essays by M. M. Bakhtin. Tradução Caryl Emerson e Michael Holquist. Austin: University of Texas Press, 1981. 433p.

BAKHTIN, Mikhail M. Problems of Dostoevsky's poetics. Trans. C. Emerson. Minneapolis:University of Minneapolis Press, 1984. 333p.

BAKHTIN, Mikhail M. Estética da Criação Verbal. São Paulo: Martins Fontes, 1992. 476p.

BENGTSSON, Jan. What is reflection? On reflection in the teaching profession and teacher education. Teachers and Teaching: theory and practice, vol. 1, n. 1, p. 23-32, 1995.

BRAY, John.; LEE, Joyce.; SMITH, Linda; YORKS, Lyle. Collaborative inquiry in practice: action, reflection and making meaning. Sage Publications, 2000. $162 \mathrm{p}$.

BREDO, Eric e FEINBERG, Walter. The critical approach to social and educational research. In: BREDO, Eric; FEINBERG, Walter (Ed.). Knowledge and Values in Social and Educational Research. Philadelphia: Temple University Press, 1982, p. 271-291.

CAMERON, Deborah, et. al. Researching Language: issues of power and method. Routledge, 1992. 148p.

CARDOZO, Solange de Almeida. Universidade e escola: uma via de mão dupla?. Rio de Janeiro, 2003. 99f. Dissertação (Mestrado) - Departamento de Educação, Pontifícia Universidade Católica do Rio de Janeiro, 2003.

CARR, Wilfred; KEMMIS, Stephens. Becoming critical: education, knowledge and action research. New York: Routledge, 1986. 264p.

CHEYNE, Allan; TARULLI, Donato. Dialogue, difference, and the "third voice" in the zone of proximal development. Disponível em: <http://webpages.charter.net/ schmolze/vygotsky/bakhtin.html>. Acessado em: 24 jun. 2004. 
COLE, Michael; ENGESTRÖM, Yrjö. A cultural-historical approach to distributed cognition. In: SALOMON, Gabriel (Ed.). Distributed Cognition: psychological and educational considerations. Cambridge University Press, 1993 , p. $1-46$.

DIETZSCH, Mary Julia M. Universidade e escola pública atuando em parceria. Cadernos de Pesquisa, São Paulo, n. 94, p. 74-81, ago. 1995.

ENGESTRÖM, Yrjö; ENGESTRÖM, Ritva; SUNTIO, Arja. Can school communities learn to master its own future? An activity-theoretical study of expansive learning among middle school teachers. In: WELLS, Gordon; CLAXTON, Guy (Ed.). Learning for life in the 21st century: sociocultural perspectives on the future of education. London: Blackwell, 2002, p. 211-224. ENGESTRÖM, Yrjö. Learning by expanding: an activity-theoretical approach to developmental research. Helsisnki: Orienta-Konsultit, 1987. Disponível em: $<$ http://lchc.edu/MCA/Paper?Engestrom/expanding/ch1.htm >. Acessado em: 28 out. 2003.

ENGESTRÖM, Yrjö. Teachers as collaborative thinkers: activity-theoretical study of an innovative teacher team. In: CARLGREN, Ingrid etal., (Ed.). Teachers' minds and actions: research on teachers' thinking and practice. Falmer Press. 1994. p. 43-61.

ENGESTRÖM, Yrjö. Development as breaking away and opening up: a challenge to Vygotsky and Piaget. In: RÜCKRIEM, Georg (Ed.). Developmental Work Research: expanding activity theory in practice. Berlin: Lehmanns Media, 1996/2005. p.37-48.

ENGESTRÖM, Yrjö. Activity Theory and individual and social transformation. In: ENGESTRÖM, Yrjö; MIETTINEM, Reijo; PUNAMAKI, Raija (Ed.). Perspectives on activity theory. Cambridge University Press, 1999. p. 19-38.

ENGESTRÖM, Yrjö. Expansive Learning at work: toward an activity theoretical reconceptualization. In: RÜCKRIEM, Georg (Ed.). Developmental Work Research: expanding activity theory in practice. Berlin: Lehmanns Media, 2001/ 2005. p.59-87.

FARACO, Carlos A. Linguagem e Diálogo: as idéias lingüísticas do círculo de Bakhtin. Curitiba: Criar Ediçōes, 2003. 136p.

FENDLER, Lynn. Teacher reflection in a hall of mirrors: historical influences and political reverberations. Educational Researcher, v. 32, n. 3, p. 16-25, April 2003. FOERSTE, Erineu. Parceria na formação de professores. São Paulo: Cortez, 2005. 168p. FREEMAN, Donald; RICHARDS, Jack C. (Ed.). Teacher Learning in Language Teaching. Cambridge: Cambridge University Press, 1996. 400p. 
FREIRE, Paulo. Pedagogia do Oprimido. 17. ed. Rio de Janeiro: Terra e Paz, 1970/ 1987. $184 \mathrm{p}$.

FREITAS, Maria Teresa de Assunção. A pesquisa na perspectiva sócio-histórica: um diálogo entre paradigmas. 2003. [mimeo].

FURTOSO, Viviane, et at. Parceria universidade/escolas: conquistas e desafios na formação de professores. In: MATEUS, Elaine; QUEVEDO-CAMARGO, Gladys ; GIMENEZ, Telma (Org.). Ressignificaçôes do NAP: rupturas e continuidades. EDUEL, no prelo.

GIMENEZ, Kilda; MATEUS, Elaine. Rompendo barreiras em um projeto de Aprendizagem sem Fronteiras. In: TELLES, João (Org.). Dimensōes da pesquisa em educação continuada de professores (título provisório). No prelo.

GIMENEZ, Telma. Os sentidos do Projeto NAP. Londrina: EDUEL, 1999. 87p.

GIMENEZ, Telma. Criando condições para o desenvolvimento profissional continuado de professores de inglês: o Centro de Recursos do NAP. In: MATEUS, Elaine; QUEVEDO-CAMARGO, Gladys; GIMENEZ, Telma (Org.). Ressignificaçôes do NAP: rupturas e continuidades. EDUEL, no prelo.

GUTIÉRREZ, Kris D.; LÓPEZ, Patricia B,; TEJEDA, Carlos. Rethinking diversity: hibridity and hibrid language practices in the third space. Mind, Culture and Activity, v. 6, n. 4, p. 286-303, 1999.

JOHNSON, Karen. The sociocultural turn and its challenges for second language teacher education. TESOL QUARTERLY, v. 40, n.1, p. 235-257, March 2006.

KASTRUP, Virgínia. Políticas cognitivas na formação do professor e o problema do devir-mestre. Educação e Sociedade, Campinas, v. 26, n. 93, p. 1273-1288, Set./Dez. 2005. Disponível em: <http://www.cedes.unicamp.br>. Acessado em: 14 jun. 2008.

KLEIMAN, Angela (Org.). A formação do professor: perspectivas da Lingüística Aplicada. Campinas: Mercado de Letras, 2001. 342p.

LAVE, Jean. Teaching, as learning, in practice. Mind, Culture and Activity, v. 3, n. 3, p. 149-164, 1996.

LAVE, Jean; WENGER, Etienne. Situated Learning: legitimate peripheral participation. Cambridge University Press, 1991. 138p.

LEONTIEV, Alexis. Uma contribuicao a teoria do desenvolvimento da psique infantil. In: VYGOTSKY, L.S.; LURIA, A.R.; LEONTIEV, A.N. Linguagem, desenvolvimento e aprendizagem. Trad. Maria da Penha Villalobos. São Paulo: Icone: Editora da Universidade Estadual de São Paulo, 1998, p. 59-83. 
LIBERALI, Fernanda. A formação crítica do educador na perspectiva da Lingüística Aplicada. In: ROTTAVA, Lucia (Org.). Ensinolaprendizagem de Linguas: língua estrangeira. Ijui: Editora da UNIJUI, 2006.

LIBERALI, Fernanda; MAGALHĀES, Maria Cecília; FIDALGO, Sueli; LESSA, Angela . Educando para a Cidadania em Contextos de Transformação. The Especialist, v. 27, p. 169-188, 2006.

MATEUS, Elaine. Atividade de aprendizagem colaborativa e inovadora de professores: ressignificando as fronteiras dos mundos universidade-escola. 2005. 327 fl. Tese (Doutorado em Lingüística Aplicada e Estudos da Linguagem) LAEL, Pontifícia Universidade Católica de São Paulo, São Paulo. 2005.

MATEUS, Elaine. Aprendizagem colaborativa de professores de inglês: uma experiência de encontro da universidade com a escola. In: Anais do XIII ENDIPE - Encontro Nacional de Didática e Prática de Ensino. Universidade Federal de Pernambuco, Recife, 2006. p. 1479-1496.

MATEUS, Elaine. Aprendizagem sem Fronteiras: ressignificando os limites da formação inicial e contínua de professores. In: ABRAHÃO, M.H.; GIL, G.; RAUBER, A.C. (Org.). Anais do I Congresso Latino-Americano sobre Formação de Professores de Linguas. Florianópolis, UFSC, 2007, p. 672-689.

MATEUS, Elaine. Em busca de outros modos de com-viver. In: MATEUS, Elaine; QUEVEDO-CAMARGO, Gladys; GIMENEZ, Telma (Org.). Ressignificaçôes do NAP: rupturas e continuidades. EDUEL, no prelo.

MATEUS, Elaine; PICONI, Larissa. Aprendizagem colaborativa de professores em formação inicial e contínua: investigando práticas discursivas. In: VIII Congresso Brasileiro de Lingüística Aplicada, 2007, Brasília. Anais do VIII CBLA, 2007.

MATEUS, Elaine; QUEVEDO-CAMARGO, Gladys; GIMENEZ, Telma (Org.). Ressignificações do NAP: rupturas e continuidades. EDUEL, no prelo.

MATUSOV, Eugene; HAYES, Renée. Building a community of educators versus effecting conceptual change in individual students: multicultural education for pre-service teachers. In: WELLS, Gordon; CLAXTON, Guy (Ed.). Learning for life in the $21^{\text {st }}$ century: sociocultural perspectives on the future of education. London: Blackwell, 2002, p. 239-251.

MATUSOV, Eugene. Intersubjectivity as a way of informing teaching design for a community of learners classroom. Teaching and Teacher Education, v. 17, p. 383-402, 2001.

MOITA LOPES, Luiz Paulo da. Contextos institucionais em Lingüística Aplicada: novos rumos. Intercâmbio, v. 5, p. 3-14, 1996. 
MOLL, Luis.; ARNOT-HOPFFER, Elizabeth. Sociocultural Competence in Teacher Education. Journal of Teacher Education. v. 56, n. 3, p.242-247, 2005. NEWMAN, Fred; HOLZMAN, Lois. Lev Vygotsky: cientista revolucionario. Trad. Marcos Bagno. São Paulo: Edições Loyola, 1993/2002. 241p.

NYSTRAND, Martin; GAMORAN, Adam; KACHUR, Robert; PRENDERGAST, Catherine. Opening Dialogue: understanding the dynamics of language learning in the English classroom. New York: Teachers College Press, 1997. 141p.

ORTENZI, Denise; GIMENEZ, Telma; CRISTOVÃO, Vera; FURTOSO, Viviane; PERIN, Jussara. Interação Universidade-escola na Formação de Professores de Inglês: experiências brasileira e norte-americana. In: XII ENDIPE - Encontro Nacional de Didática e Prática de Ensino, 2004, Curitiba. Anais do XII ENDIPE. Curitiba : Pontifícia Universidade Católica do Paraná, v. 1, 2004, p. 239-245.

REALI, Aline Maria; TACREDI, Regina Maria. Desenvolvendo uma metodologia de aproximação entre a escola e as famílias dos alunos com a parceria da universidade. Anais do IV SEMPE - Seminário de Metodologia para Projetos de Extensão, São Carlos, ago. 2001, p 29-31.

RICHARDS, Jack C. Beyond Training. Cambridge: Cambrigde University Press, 1998. 224p.

RICHARDS, Jack C.; NUNAN, David (Ed.). Second Language Teacher Education. Cambridge: Cambrigde University Press, 1990. 352p.

ROGOFF, Barbara. Observing sociocultural activity on three planes: participatory appropriation, guided participation, and apprenticeship. In: WERTSCH, J.; DEL RIO, P.; ALVAREZ, A. (Ed.). Sociocultural studies of the mind. Cambridge University Press, 1995, p. 139-164.

ROGOFF, Barbara. The cultural nature of human development. Oxford University Press, 2003. 448p.

ROTH, Wolff-Michael; TOBIN, Kenneth. The implications of coteaching/ cogenerative dialogue for teacher evaluation: learning from multiple perspectives of everyday practice. Journal of Personnel Evaluation in Education, v. 15, n.1, p. 7-29, 2001.

ROTH, Wolff-Michael; TOBIN, Kenneth. Redesigning an "urban" teacher education program: an activity theory perspective. Mind, Culture and Activity, vol.9, n.2, p. 108-131, 2002-a.

ROTH, Wolff-Michael; TOBIN, Kenneth. At the elbow of another: learning to teach by coteaching. New York. Lang, 2002-b. 340p. 
ROTH, Wolff-Michael; TOBIN, Kenneth. Coteaching: from praxis to theory. Teachers and Teaching: theory and practice. v. 10, n. 2, p. 161-180, April 2004. ROTH, Wolff-Michael; LAWLESS, Daniel; TOBIN, Kenneth. Towards a Praxeology of Teaching. Canadian Journal of Education, v. 25, n. 1, p. 1-15, 2000. SMAGORINSKY, Peter; COOK, Leslei S. e JOHNSON, Tara S. The twisting path of concept development in learning to teach. Teachers College Record. v. 105, n. 8, p. 1399-1436, October 2003.

SMAGORINSKY, Peter; COOK, Leslei S., MOORE, Cynthia; JACKSON, Alecia Y.; FRY Pamela G. Tensions in learning to teach: accommodation and the development of teaching identity. Journal of Teacher Education, v. 55, n. 1, p. 8-24, January/February 2004.

STETSENKO, Anna; ARIEVITCH, Igor. M. Vygotskian collaborative project of social transformation: history, politics, and practice in knowledge construction. International Journal of Critical Psychology, v. 12, n. 4, p. 58-80, 2002.

VADEBONCOEUR, Jennifer A. Child development and the purpose of education: a historical context for constructivism in teacher education. In: RICHARDSON, Virginia (Ed.). Constructivist teacher education: building new understandings. Washington: The Falmer Press, 1997, p. 15-37

VYGOTSKY, Lev Semyonovitch. A Formação Social da Mente: o desenvolvimento dos processos psicológicos superiores. Orgs. Michael Cole et al., 1978. Trad. José Cipolla Neto et al. 6a. Edição. São Paulo: Martins Fontes, 1998. 191p.

WALLACE, Michael J. Training Foreign Language Teachers: a reflective approach. Cambridge: Cambridge University Press, 1991. 190p.

WERTSCH, James. Voices of the mind: a sociocultural approach to mediated action. Cambridge University Press, 1991. 220p.

ZEICHNER, Kenneth. Para além da divisão entre professor-pesquisador e pesquisador acadêmico. In: GERALDI, Corina; FIORENTINI, Dario; PEREIRA, Elisabete (Org.). Cartografia do trabalho docente: professor(a)pesquisador(a). Campinas: Mercado de Letras, 1998, p. 207-236.

ZEICHNER, Kenneth. Educating reflective teachers for learner centerededucation: possibilities and contradictions. In: GIMENEZ, Telma (Org.). Ensinando e aprendendo inglês na universidade: formação de professores em tempos de mudança. Londrina: ABRAPUI, 2003, p. 3-19.

Recebido em julho de 2008. Aprovado em dezembro de 2008. 